\title{
Aplikasi Turbin Ventilator Untuk Optimasi Daya Output Panel Surya
}

\author{
La Bima $^{1^{*}}$, Prihadi Murdiyat ${ }^{2}$ \\ 1,2 Jurusan Teknik Elektro, Politeknik Negeri Samarinda, Samarinda 75131, Indonesia \\ *labima@polnes.ac.id
}

\begin{abstract}
Solar Power Plants are potentially to deployed in many parts of Indonesia, as their average power is 4 $\mathrm{kWh} / \mathrm{m}^{2}$. However, the power is often less than it is expected. The reduce of power, particularly in the bright day, is resulted by the increase of panel surface temperature. To overcome such problem, a prototype that uses a roof ventilator turbine has been realized in this research. To find the effectivity of the cooler utilizing ventilator turbine, the output power of solar panel with ventilator was compared with the output power of panel without ventilator. The parameters that were measured are the sunlight power, panel surface temperature, panel voltage and current outputs, and the power output. The load during measurement were solar charge controller, battery, and inverter. The observation result shows that the power generated by the panel with ventilator is higher than the power generated by panel without ventilator. For the circuit without load of 100watt light bulb, the efficiency index is between 3.05 and 8.89, while for the circuit with the load of 100watt light bulb, the efficiency index is between 0,65 and 1,09
\end{abstract}

Keywords: Solar Power Plants, temperature, efficiency, to cool off, ventilator turbine.

\begin{abstract}
Abstrak: Pembangkit Listrik Tenaga Surya (PLTS) berpotensi untuk dibangun di hampir seluruh daerah di Indonesia, karena mempunyai daya rata-rata sebesar $4 \mathrm{kWh} / \mathrm{m}^{2}$. Namun seringkali daya yang dihasilkan oleh panel surya lebih kecil dari daya yang diperkirakan. Penurunan daya, terutama pada siang hari saat terik, disebabkan oleh peningkatan temperature permukaan panel. Untuk mengatasi hal itu sebuah prototipe pendingin dengan menggunakan turbin ventilator atap telah dibuat pada penelitian ini. Untuk mengetahui efektifitas pendingin dengan ventilator daya yang dihasilkan oleh panel dengan ventilator dibandingkan dengan daya panel tanpa ventilator. Parameter-parameter yang diukur adalah daya cahaya matahari, temperatur permukaan panel surya, tegangan dan arus keluaran panel, sedangkan daya keluarannya dihitung. Beban saat pengukuran adalah solar charge controller, baterai, dan inverter. Hasil observasi menunjukkan bahwa daya yang dihasilkan oleh panel dengan ventilator lebih tinggi daripada daya panel tanpa ventilator. Untuk pengukuran tanpa beban lampu 100 watt, indeks efisiensi daya keluaran adalah antara 3,05 hingga 8,89. Sementara untuk pengukuran dengan beban lampu 100 watt indeks efisiensi daya keluarannya adalah antara 0,65 hingga 1,09.
\end{abstract}

Kata kunci : PLTS; temperatur; efisiensi; mendinginkan, turbin ventilator.

\section{PENDAHULUAN}

Berdasarkan geografisnya yang terletak di sekitar khatulistiwa, hampir seluruh daerah di Indonesia berpotensi untuk mengembangkan PLTS dengan daya rata-rata mencapai $4 \mathrm{kWh} / \mathrm{m}^{2}$. Kawasan Barat Indonesia memiliki distribusi penyinaran sekitar $4,5 \mathrm{kWh} / \mathrm{m}^{2} /$ hari dengan variasi bulanan $10 \%$, sementara kawasan Timur Indonesia memiliki distribusi penyinaran sekitar $5,1 \mathrm{kWh} / \mathrm{m}^{2} / \mathrm{hari}$ dengan variasi bulanan sekitar 9\% [1]. Potensi ini perlu dimanfaatkan dengan baik dengan cara mempercepat pembangunan PLTS di berbagai kawasan Indonesia [2].

Tetapi, pada kenyataannya, seringkali daya output yang dihasilkan oleh PLTS tidak sebesar yang direncanakan. Salah satu penyebabnya adalah peningkatan intensitas sinar matahari yang tinggi juga menyebabkan peningkatan suhu sel surya. Peningkatan suhu sel surya di atas $25^{\circ} \mathrm{C}$ akan diikuti penurunan daya output. Karena suhu optimal operasi sel surya adalah $25^{\circ} \mathrm{C}$. Setiap peningkatan $1{ }^{\circ} \mathrm{C}$ dari $25^{\circ} \mathrm{C}$ akan menyebabkan penurunan daya sekitar $0,4 \%$ dari total daya yang dihasilkan [3].

Penurunan daya output sel surya yang berarti juga penurunan daya output panel surya, jika terjadi pada system off grid di mana baterai yang ada perlu diisi agar dapat digunakan untuk memberikan daya listrik pada malam harinya, maka baterai tidak akan terisi penuh. Akibatnya bermacam-macam. 
Pada aplikasi penerangan jalan umum bertenaga surya misalnya, lampu tidak akan menyala hingga pagi. Begitu juga pada system offgrid pada PLTS komunal. Selain permasalahan tersebut, baterai akan mudah rusak.

Agar tidak membawa kerugian daya, maka peningkatan temperature pada permukaan panel surya perlu dikurangi dengan cara mendinginkannya. Pada penelitian ini dibangun sebuah prototype pendingin yang menggunakan turbin ventilator untuk menghisap udara panas di atas permukaan. Selanjutnya percobaan diset dengan kondisi di mana sebuah panel surya menggunakan pendingin turbo ventilator, sementara satu panel lainnya tidak menggunakan ventilator. Kemudian mulai dari tanggal 20 Oktober 2020 hingga 2 Nopember 2020 dilakukan pengukuran intensitas cahaya matahari, tegangan dan arus listrik output panel surya. Selanjutnya hasilnya dianalisis dan dibandingkan.

Penelitian-penelitian tentang pendingin panel surya telah dilakukan sebelumnya oleh beberapa pihak. Pendingin dengan menggunakan air yang disiramkan pada permukaan panel dilakukan di Pontianak [3]. Di sini air dialirkan tiap 5 menit dengan dengan lama penyiraman 20 detik. Sebuah pompa digunakan untuk mengalirkan air ke permukaan panel. Hasil pengukuran selama 3 hari menunjukkan bahwa daya keluaran panel meningkat sebesar rata-rata $4 \%$.

Penelitian serupa juga dilakukan oleh Pido dkk. di Makassar [4]. Air hanya disiramkan saat dilakukan pengukuran. Pengukuran dilakukan untuk membandingkan tegangan dan arus keluaran untuk beberapa nilai beban $\mathrm{R}$ dengan masing-masing dilakukan pada kondisi tanpa pendingin (air), dan air mengalir dengan debit $50 \mathrm{ml} / \mathrm{s}, 67 \mathrm{ml} / \mathrm{s}, 100 \mathrm{ml} / \mathrm{s}, 150 \mathrm{ml} / \mathrm{s}$. Hasil penelitian menunjukkan bahwa pada intensitas yang sama, daya keluaran panel tanpa pendingin adalah $6,8 \mathrm{~W}$ dengan efisiensi 1,54 \%, sedang daya keluaran panel dengan pendingin air berdebit $150 \mathrm{ml} / \mathrm{s}$ adalah sebesar 7, $3 \mathrm{~W}$ dengan efisiensi $1,2 \%$.

Metode pendingin permukaan dengan menggunakan air uyang terbukti cukup efektif belum tentu dapat digunakan jika pada daerah tertentu air cukup sulit untuk diperoleh. Selain itu, diperlukannya pompa untuk menyiram permukaan panel tentu membutuhkan tenaga listrik yang diperoleh juga dari panel surya. Pada penelitian ini digunakan pendinginan dengan metode lain yaitu menarik udara panas di permukaan panel surya dengan menggunakan turbin ventilator. Alat ini sejenis dengan exhaust fan atau roof fan yang fungsinya adalah menghisap udara panas yang ada dalam ruangan [5]. Ketika angin bertiup dan memutar alat ini, maka akan terdapat gaya sentrifugal yang menaril udara panas di dalam ruangan.

\section{METODE PENELITIAN}

Pada penelitian ini dibuat system pendingin permukaan panel surya yang terbagi atas tiga bagian yaitu: bed, turbin ventilator, dan pipa penghubung. Bentuk bed ditunjukkan dalam Gambar 1a. Tampak bahwa pada bagian samping bed terdapat lubang-lubang yang akan berfungsi untuk menghisap udara panas di atas permukaan panel surya, jika panel surya diletakkan di atasnya. Bagian ujung bed yang berupa pipa akan dihubungkan dengan unit turbin ventilator dengan konstruksi seperti pada Gambar $1 b$. 

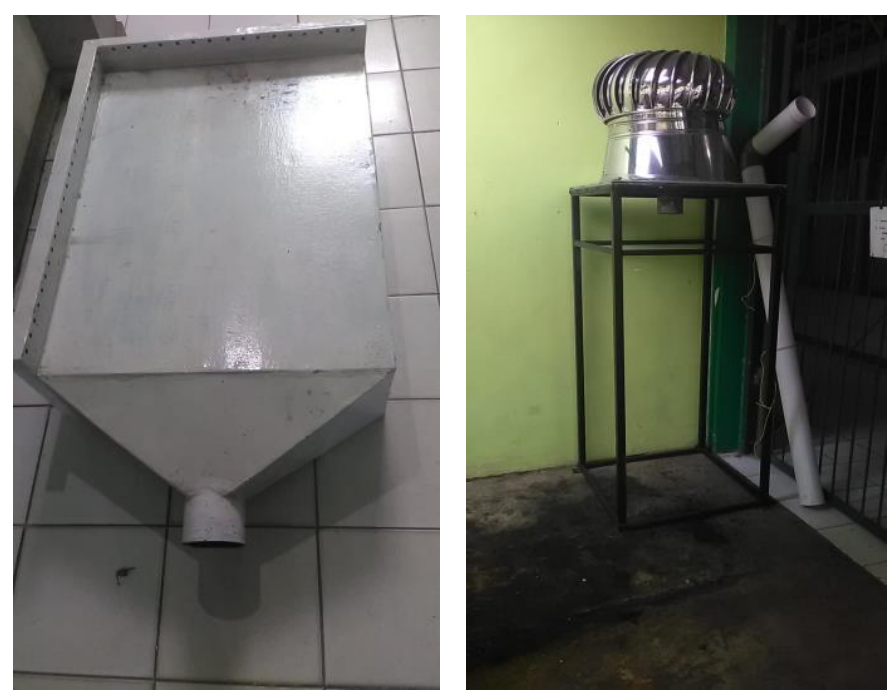

Gambar 1. a) Bed Pendingin b) Turbin Ventilator

Ketika telah disatukan dan dipasang panel surya, tampilan panel surya berpendingin akan tampak seperti pada Gambar 2. Beban dari panel surya adalah solar battery charger dengan kapasitas $30 \mathrm{~A}$, baterai VRLA Deep Cycle $12 \mathrm{~V} 50 \mathrm{Ah}$, dan inverter dengan kapasitas $500 \mathrm{~W}$ yang digunakan untuk menyuplai sebuah lampu pijar $100 \mathrm{~W}$. Beban yang sama juga dipasang pada unit panel surya tanpa pendingin.

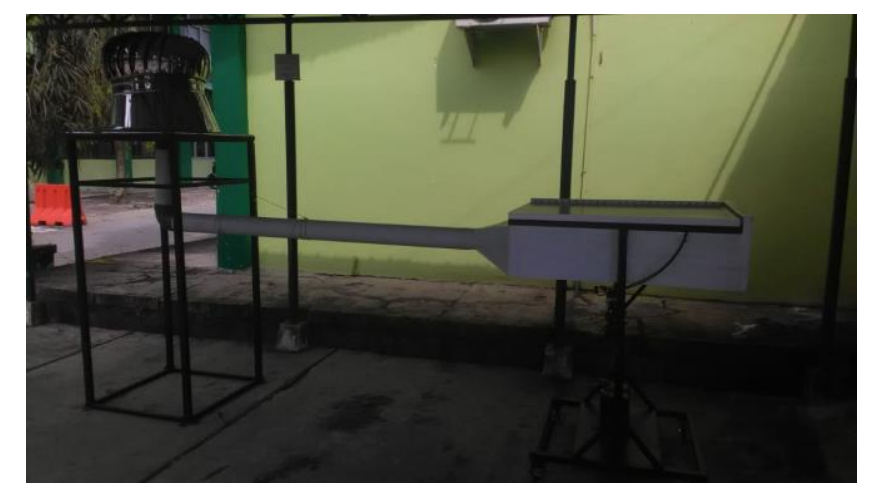

Gambar 2. Konstruksi Lengkap Panel Surya Dengan Pendingin Turbin Ventilator

Untuk pengukuran selama dua minggu, kedua unit panel surya diletakkan di tempat parkir Laboratorium Jurusan Teknik Elektro, seperti ditunjukkan dalam Gambar 3. Pengukuran dilakukan satu jam sekali, mulai dari jam 09:00 pagi hingga 15:00. Pada waktu tersebut, kedua panel sudah terpapar cahaya matahari, kecuali saat mendung atau hujan. 


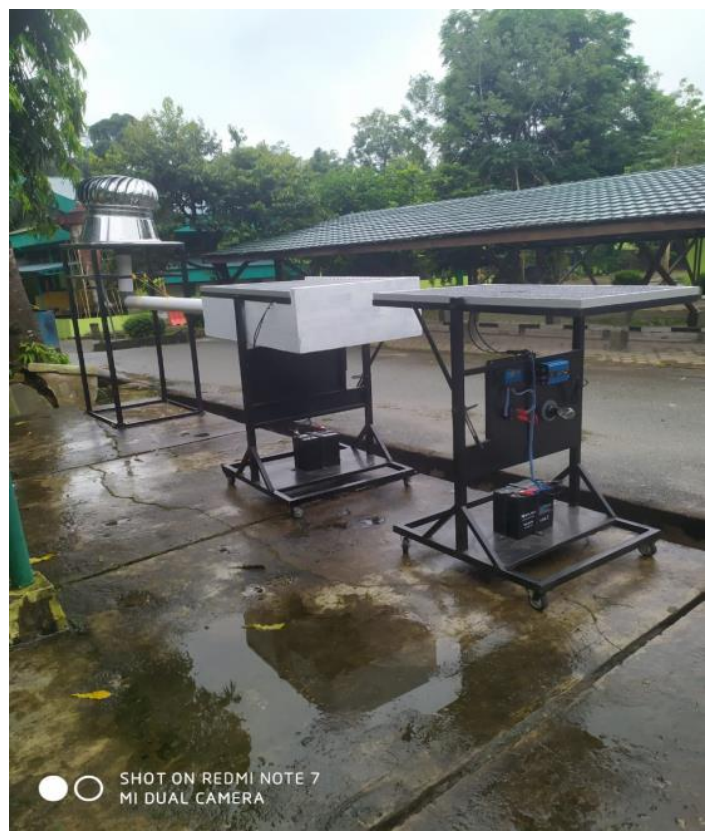

Gambar 3. Letak Kedua Panel Surya Saat Dilakukan Pengamatan.

Alat yang digunakan untuk melakukan pengukuran adalah: Voltmeter/ Amperemeter Digital Richmeter 101, Solar Powermeter SM-206-SOLAR, InfraRed Thermometer 320-EN-00. Besaran yang diukur adalah daya yang dihasilkan oleh sinar matahari, temperatur permukaan panel, daya yang dihasilkan oleh sinar matahari, tegangan dan arus keluaran panel pada saat lampu dinyalakan dan dimatikan.

\section{HASIL DAN PEMBAHASAN}

Untuk hasil pengukuran temperatur rata-rata permukaan panel tanpa dan dengan ventilator selama dua minggu mulai dari jam 9:00 hingga 15:00 dalam perbandingannya dengan intensitas cahaya, ditunjukkan dalam Tabel 1.

Tabel 1. Perbandingan Suhu Panel Tanpa dan Dengan Ventilator Pada Intensitas yang Dihasilkan

\begin{tabular}{|c|c|c|c|c|}
\hline \multirow{2}{*}{ Jam } & $\begin{array}{c}\text { Intensitas cahaya } \\
\text { Matahari }\left(\mathrm{W} / \mathrm{m}^{2}\right)\end{array}$ & $\begin{array}{c}\text { Temperatur } \\
\text { permukaan panel } \\
\text { surya tanpa ventilator } \\
\left({ }^{\circ} \mathrm{C}\right)\end{array}$ & $\begin{array}{c}\text { Temperatur } \\
\text { permukaan panel } \\
\text { surya dengan } \\
\text { ventilator }\left({ }^{\circ} \mathrm{C}\right)\end{array}$ & $\begin{array}{c}\text { Perbedaan } \\
\text { temperatur }\left({ }^{\circ} \mathrm{C}\right)\end{array}$ \\
\hline 09.00 & 14,54 & 34,93 & 38,21 & 3,28 \\
\hline 10.00 & 17,56 & 41,64 & 46,93 & 5,29 \\
\hline 11.00 & 18,93 & 45,07 & 47,93 & 2,86 \\
\hline 12.00 & 20,86 & 50,57 & 56,86 & 6,29 \\
\hline 13.00 & 19,19 & 46,01 & 52,64 & 3,03 \\
\hline 14.00 & 16,10 & 44,14 & 47,14 & 4,18 \\
\hline
\end{tabular}

Tampak bahwa temperatur permukaan panel dengan ventilator justru lebih panas dibanding panel tanpa ventilator dengan beda suhu $2,86^{\circ} \mathrm{C}$ ke atas. Hasil yang tidak sesuai dengan yang diinginkan ini kemungkinan besar disebabkan oleh tidak adanya lubang pada permukaan bed di mana panel surya diletakkan. Akibatnya sedikit jalan bagi udara panas di bawah panel yang dapat mengalir keluar. Agar metode pendinginan dengan ventilator ini dapat bekerja sesuai yang diinginkan, perlu dibuat banyak 
lubang di permukaan tersebut. Selanjutnya, mengacu pada [3] di mana setiap peningkatan $1^{\circ} \mathrm{C}$ dari $25^{\circ} \mathrm{C}$ akan menyebabkan penurunan daya sekitar $0,4 \%$ dari total daya yang dihasilkan, maka dengan hasil tersebut, daya yang dihasilkan oleh panel surya dengan ventilator akan lebih rendah dibanding panel surya tanpa ventilator.

Tetapi, pada perbandingan antara daya keluaran panel dengan ventilator dan tanpa ventilator seperti yang ditunjukkann dalam Tabel 2, daya yang dihasilkan oleh panel dengan ventilator justru lebih tinggi dibanding daya panel tanpa ventilator. Sebagai catatan, daya diperoleh dari perkalian antara tegangan dan arus yang terukur pada keluaran panel. Keluaran panel surya terhubung pada bebanbeban: solar battery charger dengan kapasitas 30 A, baterai VRLA Deep Cycle 12 V 50 Ah, dan inverter dengan kapasitas $500 \mathrm{~W}$ yang digunakan untuk menyuplai sebuah lampu pijar $100 \mathrm{~W}$. Pengukuran dilakukan dalam dua cara, yaitu ketika lampu 100 Watt padam dan ketika lampu menyala.

Tabel 2. Perbandingan Daya Output Tanda dan Dengan Ventilator Dengan Lampu 100 W Padam

\begin{tabular}{|c|c|c|c|c|c|}
\hline Jam & $\begin{array}{c}\text { Daya output } \\
\text { panel tanpa } \\
\text { ventilator (watt) }\end{array}$ & $\begin{array}{c}\text { Daya output } \\
\text { panel dengan } \\
\text { ventilator (watt) }\end{array}$ & $\begin{array}{c}\text { Efisiensi panel } \\
\text { tanpa ventilator } \\
(\%)\end{array}$ & $\begin{array}{c}\text { Efisiensi panel } \\
\text { dengan } \\
\text { ventilator }(\%)\end{array}$ & Indeks efisiensi \\
\hline 09.00 & 3,54 & 31,41 & 7,65 & 67,85 & 8,89 \\
\hline 10.00 & 3,44 & 26,86 & 6,15 & 48,05 & 7,80 \\
\hline 11.00 & 5,33 & 37,57 & 8,85 & 62,35 & 7.04 \\
\hline 12.00 & 9,34 & 28,56 & 14,06 & 43,00 & 3,05 \\
\hline 13.00 & 5,28 & 28,11 & 8,65 & 46,01 & 5,32 \\
\hline 14.00 & 7,16 & 36,59 & 13,96 & 71,36 & 5,11 \\
\hline 15.00 & 7,14 & 26,15 & 14,54 & 53,25 & 3,66 \\
\hline
\end{tabular}

Dari rata-rata yang diperoleh dari hasil pengukuran lampu $100 \mathrm{~W}$ padam, tampak bahwa daya dan efisiensi yang dihasilkan oleh panel dengan ventilator lebih tinggi dibanding tanpa ventilator. Indeks efisiensinya bernilai antara 3,05 hingga 8,89. Mengingat bahwa temperatur panel dengan ventilasi lebih tinggi daripada panel tanpa ventilasi, hasil ini tidak sesuai pernyataan pada [3][4] bahwa panel dengan temperatur lebih tinggi akan berkurang daya keluarannya. Ketidak sesuaian ini sangat mungkin karena pengukuran pada [3][4] tidak menggunakan beban, sementara pada peneltian ini digunakan berbagai beban seperti disampaikan pada paragraph sebelumnya.

Pada penelitian ini, daya yang terukur menunjukkan bahwa tegangan dan arus yang dihasilkan oleh panel dengan ventilasi muncul karena baterai belum terisi penuh Sebaliknya, pada panel tanpa ventilator, baterai terisi penuh sehingga panel tidak mengalirkan arus ke baterai. Pengisian baterai yang lebih cepat pada panel tanpa ventilator disebabkan oleh tegangan keluaran yang lebih tinggi dibanding panel dengan ventilator yang keluarannya lebih rendah karena panel lebih panas. Pada penelitian ini, analisa tersebut belum sempat dibuktikan karena pada saat pengukuran, tegangan dan arus yang mengalir ke baterai tidak diukur.

Untuk perbandingan daya output dan efisiensi daya panel surya tanpa dan dengan ventilator pada kondisi berbeban, hasilnya ditunjukkan dalam Tabel 3. Dari tabel tampak bahwa daya ouput panel dengan ventilator tidak selalu lebih tinggi dibanding daya output panel tanpa ventilator. Selisih antara keduanyapun juga tidak terlalu besar. Maka indeks efisiensinyapun maksimal hanya mencapai maksimal 1,09, yang artinya pemasangan ventilator belum menunjukkan perbaikan yang signifikan terhadap efisiensi daya. 
Tabel 3. Perbandingan Daya Output Tanda dan Dengan Ventilator Dengan Lampu 100 W Menyala

\begin{tabular}{|c|c|c|c|c|c|}
\hline Jam & $\begin{array}{c}\text { Daya output } \\
\text { panel tanpa } \\
\text { ventilator (watt) }\end{array}$ & $\begin{array}{c}\text { Daya output } \\
\text { panel dengan } \\
\text { ventilator (watt) }\end{array}$ & $\begin{array}{c}\text { Efisiensi panel } \\
\text { tanpa ventilator } \\
(\%)\end{array}$ & $\begin{array}{c}\text { Efisiensi panel } \\
\text { dengan } \\
\text { ventilator }(\%)\end{array}$ & Indeks efisiensi \\
\hline 09.00 & 18,31 & 19,86 & 39,56 & 42,92 & 1,09 \\
\hline 10.00 & 41,67 & 45,28 & 74,55 & 81,01 & 1,09 \\
\hline 11.00 & 39,74 & 25,92 & 65,95 & 43,01 & 0,65 \\
\hline 12.00 & 56,58 & 49,62 & 85,19 & 74,71 & 0,87 \\
\hline 13.00 & 45,02 & 47,88 & 73,70 & 78,37 & 1,06 \\
\hline 14.00 & 43,25 & 41,61 & 84,36 & 81,16 & 0,96 \\
\hline 15.00 & 26,28 & 28,15 & 53,52 & 57,33 & 1,07 \\
\hline
\end{tabular}

\section{KESIMPULAN}

Kesimpulan yang diperoleh dari hasil penelitian ini adalah bahwa dengan kondisi dibebani oleh baterai solar charge controller, baterai, dan inverter, daya yang dihasilkan oleh panel surya dengan ventilator lebih besar dari yang dihasilkan panel tanpa ventilator dengan indeks efisiensi antara 3,05 hingga 8,89 . Sementara untuk beban yang sama tetapi ditambah dengan lampu 100 watt, daya yang dihasilkan oleh panel surya dengan ventilator tetap lebih besar daripada yang dihasilkan oleh panel tanpa ventilator dengan indeks efisiensi antara 0,65 hingga 1,09.

Untuk mengurangi temperatur permukaan yang masih tinggi, untuk penelitian selanjutnya, bagian atas bed yang ditumpangi oleh panel diberikan lubang-lubang, sehingga udara panas yang terhisap turbin tidak hanya di sisi atas, tetapi juga di sisi bawah. Selain itu saat pengukuran dilakukan, beban berupa SCC, baterai, inverter dan lampu mungkin diganti dengan sebuah resistor saja, untuk menghilangkan pengaruh dari beban-beban tersebut.

\section{UCAPAN TERIMA KASIH}

Ucapan terima kasih kepada Pusat Penelitian dan Pengabdian Masyarakat (P3M) Politeknik Negeri Samarinda yang telah memberikan bantuan pendanaan untuk melakukan penelitian ini

\section{DAFTAR PUSTAKA}

[1] R. A. Nugroho, et al. Memaksimalkan Daya Keluaran Sel Surya Dengan Menggunakan Cermin Pemantul Sinar Matahari, Transient Volume 3 Nomor 03 halaman 409-414, Semarang, Teknik Elektro UNDIP; 2014

[2] M. F. Firdaus, Kajian Potensi Energi Surya, Publikasi Matahari, https://icareindonesia.org/kajian-potensi-energi-surya-di-indonesia-2/ (22 Juni 2017), Uploud 4 Maret 2020.

[3] Afriandi, I. Yusuf, A. Hiendro, "Implementasi Water Cooling Sistem Untuk Menurunkan Temperatur Losses Pada Panel Surya”, Jurnal Teknik Elektro Universitas Tanjung Pura 2(1), 2017.

[4] R. Pido, S. Kimran, dan Mahmuddin, "Analisa Pengaruh Pendingin Sel Surya Terhadap Daya Keluaran dan Efisiensi”, Jurnal Teknologi 19(1), 2018.

[5] Mingseli, Pengertian, Fungsi dan Cara kerja Turbin Ventilator Atap, https://www.mingseli.id/2018/06/pengertian-fungsi-cara-kerja-turbin html, (11 Maret 2018), upload 7 Maret 2020. 